Arq. Bras. Med. Vet. Zootec., v.56, n.3, p.333-339, 2004

\title{
Efeito do dimetildioctadecilamônio na resposta imune humoral e celular de cobaios inoculados com o herpesvírus bovino-1 inativado
}

\author{
[Effect of dimethyl dioctadecyl ammonium chloride on the humoral and cellular response to inactivated bovine \\ herpesvirus-1 in guinea pigs] \\ L.C. Silva ${ }^{1}$; E. Takiuchi ${ }^{2}$; K.C. Médici ${ }^{2}$; A.F. Alfieri ${ }^{2}$; A.A. Alfieri ${ }^{2} *$ \\ ${ }^{1}$ Mestrando em Ciência Animal - Universidade Estadual de Londrina \\ ${ }^{2}$ Departamento de Medicina Veterinária Preventiva \\ Centro de Ciências Agrárias da Universidade Estadual de Londrina \\ Caixa Postal, 6001 \\ 86051-990 - Londrina, PR
}

\begin{abstract}
RESUMO
Avaliou-se o potencial adjuvante do cloreto de dimetildioctadecilamônio (DDA cloreto) em estimular as respostas imune humoral e celular, do tipo hipersensibilidade cutânea tardia (DTH), em cobaios que receberam preparações de antígeno contendo o herpesvírus bovino tipo 1 (BHV-1) inativado. Os animais foram vacinados com o BHV-1 em cinco diferentes formulações, representadas pelos grupos: Aadjuvante completo / incompleto de Freund, B- hidróxido de alumínio $\left(\mathrm{Al}(\mathrm{OH})_{3}\right)$, C- DDA cloreto, Dassociação $\mathrm{Al}(\mathrm{OH})_{3} / \mathrm{DDA}$ cloreto e E- BHV-1 em solução aquosa sem adjuvante. Os animais do grupo $\mathrm{F}$, grupo-controle negativo, foram inoculados apenas com meio de cultivo celular. Os maiores títulos de anticorpos neutralizantes do BHV-1, expressos em $\log _{2}$, foram obtidos nos grupos $\mathrm{D}$, A e C, com títulos de 6,25, 6,0 e 5,25, respectivamente. Na avaliação da DTH, os maiores aumentos na espessura da dobra da pele foram observados nos grupos A $(2,4 \mathrm{~mm}), \mathrm{C}(1,8 \mathrm{~mm})$ e D $(1,1 \mathrm{~mm})$. O DDA cloreto, utilizado tanto de forma isolada quanto em associação, determinou a potencialização das respostas imunológicas humoral e celular de cobaios imunizados com o BHV-1 inativado.
\end{abstract}

Palavras-chave: adjuvante imunológico, cloreto de dimetildioctadecilamônio, cobaio, herpesvírus bovino tipo 1

\begin{abstract}
The adjuvanticity of dimethyl dioctadecyl ammonium chloride (DDA chloride) to induce humoral and cell mediated (delayed type hypersensitivity - DTH -) immune responses was assessed in guinea pigs that received antigen preparations containing inactivated bovine herpesvirus type 1 (BHV-1). The animals were vaccinated with five different formulations, containing $B H V-1$ represented by groups: $A$ complete/incomplete Freund adjuvant, $B$ - aluminum hydroxide $\left(\mathrm{Al}(\mathrm{OH})_{3}\right), \quad C$ - $D D A$ chloride, $D$ association $\mathrm{Al}(\mathrm{OH})_{3} / \mathrm{DDA}$ and $\mathrm{E}-\mathrm{BHV}-1$ in aqueous solution without adjuvant. Group $F$ was the negative control group and the animals received only cell culture medium. The higher titers of BHV-1 neutralizing antibodies, expressed in $\log _{2}$, were obtained in groups $D, A$ and $C$ with values of 6.25, 6.0 and 5.25, respectively. In the DTH assessment, the higher increase in skin thickness was observed in group A $(2.4 \mathrm{~mm}), C(1.8 \mathrm{~mm})$ and $D(1.1 \mathrm{~mm})$. These results showed that DDA chloride used alone or in
\end{abstract}

Apoio financeiro: CNPq, CAPES e CPG/UEL

Recebido para publicação em 7 de outubro de 2002

Recebido para publicação, após modificações, em 20 de novembro de 2003

*Autor para correspondência

E-mail: alfieri@uel.br 
association to other substance boosted the humoral and cell mediated immune responses in guinea pigs immunized with inactivated BHV-1.

Keywords: immunological adjuvant, dimethyl dioctadecyl ammonium chloride, guinea pig, bovine herpesvirus type 1

\section{INTRODUÇÃO}

Vários tipos de vacinas estão disponíveis para o controle e a profilaxia de importantes infecções em medicina humana e veterinária. Excetuandose as vacinas nas quais o microrganismo está na forma atenuada, em todas as outras, para o incremento da imunogenicidade dos antígenos, são utilizadas substâncias de natureza biológica, mineral e mesmo produtos químicos sintéticos que potencializam, de forma específica, a resposta imunológica do homem e dos animais, atuando, dessa forma, como adjuvantes imunológicos (Gupta e Griffin, 1996; Hanly, 1995). Entretanto, devido principalmente a uma gama de efeitos adversos, são poucos os adjuvantes regularmente utilizados em vacinas de uso humano e animal (Gupta e Siber, 1995; Jennings, 1995).

O dimetildioctadecilamônio (DDA) é uma amina quaternária lipofílica sintética, quimicamente definida, que atua como agente surfactante e apresenta importante característica imunomoduladora. A habilidade do DDA em potencializar a resposta imunológica do homem e, principalmente, de animais vem sendo avaliada frente a antígenos de diferentes origens e complexidade, como vírus, bactérias, parasitas, toxinas, células de mamíferos, carreadoreshaptenos e peptídeos sintéticos (Hilgers e Snippe, 1992; Lindblad et al., 1997). Comparado a outros adjuvantes imunológicos, o DDA apresenta como característica um efeito estimulador da resposta humoral que pode ser classificado de moderado a intenso. Para a resposta imunológica mediada por células, especialmente a do tipo hipersensibilidade tardia (DTH), a ampla maioria dos trabalhos comprova que o DDA exerce potente efeito adjuvante (Dzata et al., 1991; Katz et al., 1993; Lillehoj et al., 1993). Vários estudos demonstraram que, para o homem e para a maioria das espécies animais, o DDA é inócuo, não provocando praticamente nenhuma reação adversa (Gupta e Siber, 1995; Hanly, 1995).
O DDA apresenta carga elétrica positiva em um ânion monovalente. Comercialmente o DDA pode ser encontrado com o ânion brometo ou cloreto e não há indicações que isto possa comprometer o potencial adjuvante (Hilgers e Snippe, 1992). Entretanto, a grande maioria dos trabalhos avalia a capacidade adjuvante do DDA brometo, sendo poucos os estudos relativos ao uso do DDA cloreto como potencializador da resposta imune (Grubhofer, 1995; Silva et al., 1998; Silva et al., 2003).

O baixo custo do DDA cloreto, produzido em grande escala e utilizado pela indústria de cosméticos, e o pequeno número de estudos conduzidos, até o momento, para a avaliação de seu potencial adjuvante têm estimulado o desenvolvimento de experimentos que avaliem a sua inocuidade e a intensidade da resposta imune humoral e celular de animais de experimento imunizados com diferentes tipos de antígenos.

O herpesvírus bovino tipo 1 (BHV-1), que acomete bovinos de aptidão leiteira e de corte, pode determinar vários sinais clínicos. Todas as formas de apresentação, e em particular as formas reprodutiva e respiratória, são de difícil diagnóstico diferencial e ocasionam prejuízos econômicos significativos à exploração pecuária (Straub, 1990). No Brasil, evidências sorológicas indicam que a infecção pelo BHV-1 está amplamente disseminada em todas as regiões, particularmente onde a pecuária bovina apresenta-se como importante atividade econômica (Richtzenhain et al., 1999; Médici et al., 2000; Cortez et al., 2001; Takiuchi et al., 2001).

Entre as várias medidas de controle e profilaxia da infecção pelo BHV-1 a vacinação é a mais amplamente utilizada (Wergifosse et al., 1997). Para isso, foram desenvolvidos diferentes tipos de vacinas contendo o BHV-1 atenuado ou inativado (Ackermann et al., 1990; Strube et al., 1996). Para o efetivo controle dos sinais clínicos determinados pelo BHV-1, o imunógeno deve providenciar bons níveis de imunidade humoral e 
celular. As vacinas com vírus atenuado, produzidas por metodologias convencionais, induzem ambos os tipos de imunidade, entretanto apresentam como desvantagem a possibilidade de provocar aborto em fêmeas gestantes (Spire et al., 1995). As vacinas com vírus inativados são seguras para todas a categorias de animais e, na dependência do adjuvante utilizado, podem induzir bons níveis de anticorpos neutralizantes (imunidade humoral). Porém, classicamente, os imunógenos que contenham microrganismos inativados são fracos indutores de imunidade do tipo celular (Gupta et al., 1995).

Se se considerar a prevalência da infecção pelo BHV-1 no rebanho bovino brasileiro, a importância da imunidade humoral e celular no controle dos sinais clínicos dessa virose e a inexistência de dados relativos ao potencial adjuvante do DDA cloreto na imunogenicidade do BHV-1, este trabalho teve como objetivo avaliar o título de anticorpos neutralizantes e a hipersensibilidade cutânea tardia de cobaios inoculados com uma formulação contendo o BHV-1 inativado e o DDA cloreto como adjuvante imunológico.

\section{MATERIAL E MÉTODOS}

$\mathrm{O}$ vírus utilizado em todos os experimentos foi o BHV-1, estirpe Los Angeles (LA) (ATCC). O antígeno viral foi produzido em células de linhagem contínua Madin Darby bovine kidney (MDBK), mantidas em meio Dulbecco modificado $^{1}$ (DMEM), suplementado com $7 \%$ de soro fetal bovino ${ }^{1}$ (SFB) livre de micoplasmas e vírus, com $55 \mu \mathrm{g} / \mathrm{ml}$ de gentamicina ${ }^{2}$ e $2,5 \mu \mathrm{g} / \mathrm{ml}$ de anfotericina $\mathrm{B}^{2}$. Para a produção do $\mathrm{BHV}-1$ em cultivo celular, a concentração do SFB presente no meio de cultura celular DMEM foi reduzida para 1\%. Após a visualização de 60 a $70 \%$ de efeito citopático (ECP), as células foram lisadas por três ciclos rápidos de congelamento/descongelamento. O título viral presente na suspensão foi calculado em dose infecciosa $50 \%$ para cultura de tecidos $\left(\mathrm{TCID}_{50}\right)$.

O BHV-1 foi inativado com 2-bromoetilimina (BEI, $10 \mathrm{mM} \mathrm{pH} 7,8$ ) por 12 horas a $25^{\circ} \mathrm{C}$. A BEI foi obtida pela ciclização da 2-bromoetilamina

\footnotetext{
${ }^{1}$ Gibco BRL, EUA.

${ }^{2}$ Sigma Co, EUA.
}

(BEA) a $37^{\circ} \mathrm{C}$ por uma hora sob condição alcalina. Após a inativação do BHV-1, a BEI foi neutralizada pela adição de tiossulfato de sódio em concentração final a 1\% (Bahnemann, 1975). Para o controle de vírus infeccioso residual a amostra inativada foi inoculada em células MDBK, sendo a presença e/ou ausência de ECP monitorada por 96 horas.

Após a obtenção do antígeno inativado foram preparadas cinco diferentes formulações de vacinas (grupos A a E). Em todos os grupos, o volume final $(2 \mathrm{ml})$ e o título do vírus $\left(10^{6,3} / \mathrm{ml}\right)$ foram constantes.

No grupo A, a vacina com os adjuvantes completo e incompleto de Freund ${ }^{2}$ (ACF e AIF) foi constituída por emulsão, com volumes iguais do antígeno inativado e do ACF (primeira dose) e do AIF (segunda dose). A estabilidade da emulsão foi avaliada pelo teste da gota (Moncada et al., 1993). Nos grupo B e C, vacinas contendo apenas hidróxido de alumínio $\left[\mathrm{Al}(\mathrm{OH})_{3}-\right.$ $10 \mathrm{mg} / \mathrm{ml}$ ] e DDA cloreto $(10 \mathrm{mg} / \mathrm{ml})$, a adsorção do antígeno foi feita de forma lenta e gradual pelo período de quatro horas, com agitação constante. Para a elaboração da vacina do grupo $\mathrm{D}$, contendo a associação $\mathrm{Al}(\mathrm{OH})_{3}$-DDA cloreto, também com $10 \mathrm{mg} / \mathrm{ml}$ de cada adjuvante, o vírus foi inicialmente adsorvido pelo $\mathrm{Al}(\mathrm{OH})_{3}$, adicionando-se posteriormente o DDA cloreto. Os grupo E e F constituíram os grupos controle, sem adjuvantes. No grupo $\mathrm{E}$ foi utilizado o BHV-1 em solução aquosa e no grupo $\mathrm{F}$, inoculação apenas com o meio de cultura celular DMEM. Todas as formulações de vacinas foram avaliadas quanto à inocuidade e à esterilidade por testes padrões conduzidos em camundongos (Code..., 1999).

Para os ensaios de potência das vacinas foram utilizados 24 cobaios albinos, com aproximadamente 300 gramas, divididos em seis grupos (A-F) constituídos de quatro animais cada. Todos os animais foram inoculados em duas ocasiões (dias 0 e 21), pela via subcutânea, com $2 \mathrm{ml}$ de vacina. No dia anterior à primeira vacinação (dia zero) e nos dias 21 (segunda dose) e 35 foram realizadas colheitas de sangue por punção cardíaca. Os soros, obtidos após a retração do coágulo sangüíneo, foram centrifugados a $1000 \times \mathrm{g} / 10 \mathrm{~min}$ e estocados a $20^{\circ} \mathrm{C}$ até a avaliação do perfil sorológico. 
A titulação dos anticorpos anti-BHV-1 foi realizada de acordo com a microtécnica de soroneutralização (SN) descrita por Britsch (1978). Após prévia inativação a $56^{\circ} \mathrm{C} / 30 \mathrm{~min}$, diluições seriadas dos soros (1:2 a 1:512), realizadas em meio DMEM, foram distribuídas em microplacas de 96 cavidades e incubadas com 100 TCID $_{50}$ da estirpe LA do BHV-1. Após incubação por uma hora a $37^{\circ} \mathrm{C}$, uma suspensão de $4 \times 10^{4}$ células MDBK em meio DMEM foi adicionada a cada cavidade e as placas foram incubadas à $37^{\circ} \mathrm{C}$ em atmosfera de $5 \%$ de $\mathrm{CO}_{2}$ por três dias. Foram consideradas positivas as diluições dos soros que inibiram $100 \%$ do ECP do BHV-1.

A avaliação da imunidade celular, aos 60 dias após a vacinação, foi feita pelo teste de hipersensibilidade cutânea tardia (DTH). Um volume de $0,1 \mathrm{ml}$ do $\mathrm{BHV}-1$ inativado, com título de $10^{6,3} / \mathrm{ml}$, foi inoculado pela via intradérmica no dorso dos cobaios de todos os seis grupos. A espessura da dobra da pele foi aferida com paquímetro no momento anterior e $72 \mathrm{~h}$ após a aplicação do antígeno viral inativado. Tanto o desenvolvimento quanto a intensidade da DTH foram avaliados pelo cálculo do aumento da espessura da dobra da pele.

Para o tratamento estatístico foi utilizada a análise de variância em blocos completos ao acaso, com nível de significância de 5\%, e para as comparações múltiplas foi empregado o teste Duncan a 5\%. Para a realização dos cálculos foi empregado o programa Statistic Analysis Systems (User's..., 1996).

\section{RESULTADOS E DISCUSSÃO}

Durante o experimento não foi observada soroconversão nos animais do grupo $F$ (controle), inoculados apenas com o DMEM. As médias dos títulos de anticorpos e os títulos mínimo e máximo, expressos em $\log _{2}$, obtidos pela técnica de SN e distribuídas por grupo de vacinas testadas, são apresentadas na Tab. 1 .

Tabela 1. Distribuição dos títulos de anticorpos neutralizantes em cobaias $(n=24)$ vacinadas com duas doses (dias zero e 21) do herpesvírus bovinos tipo 1 (títul: $10^{6,3} / \mathrm{ml}$ ) inativado e em diferentes formulações de vacinas

\begin{tabular}{lccccc}
\hline \multirow{2}{*}{ Grupo: vacina } & \multicolumn{3}{c}{ Média do título de anticorpos $\left(\log _{2}\right)$} & \multicolumn{2}{c}{ Título } \\
\cline { 2 - 6 } & Dia 0 & Dia 21 & Dia 35 & Mínimo & Máximo \\
\hline A: ACF/AIF & $<1,0$ & 1,5 & $6,0 \mathrm{AB}$ & 6,0 & 6,0 \\
$\mathrm{~B}: \mathrm{Al}(\mathrm{OH})_{3}$ & $<1,0$ & 2,0 & $5,0 \mathrm{~B}$ & 4,0 & 6,0 \\
$\mathrm{C}: \mathrm{DDA}$ & $<1,0$ & 0,75 & $5,25 \mathrm{AB}$ & 4,0 & 6,0 \\
D: $\mathrm{Al}(\mathrm{OH})_{3} / \mathrm{DDA}$ & $<1,0$ & 3,25 & $6,25 \mathrm{~A}$ & 6,0 & 7,0 \\
E: BHV-1 em solução aquosa & $<1,0$ & 0,5 & $5,0 \mathrm{~B}$ & 4,0 & 6,0 \\
F: Controle-DMEM & $<1,0$ & $<1,0$ & $<1,0 \mathrm{C}$ & $<1,0$ & $<1,0$ \\
\hline ACFyyyyyy
\end{tabular}

ACF/AIF (adjuvante completo/incompleto de Freund); $\mathrm{Al}(\mathrm{OH})_{3}$ (gel de hidróxido de alumínio);

DDA (cloreto de dimetildioctadecilamônio); $\mathrm{Al}(\mathrm{OH})_{3} / \mathrm{DDA}$ (associação gel de hidróxido de alumínio e

DDA); Controle-DMEM (meio para cultivo celular Dulbecco modificado).

Médias seguidas por letras distintas na coluna diferem entre si pelo teste Duncan $(\mathrm{P}<0,05)$.

O resultado observado no grupo E demonstra que, diferentemente do observado em camundongos (dados não mostrados), o cobaio apresenta boa resposta imune humoral frente a esse antígeno. O título médio de anticorpos neutralizantes nesse grupo foi igual ao do grupo B $(5,0)$ e semelhante ao dos grupos A $(6,0)$ e C $(5,25)$. A boa conversão sorológica pós-vacinal de cobaios frente ao BHV-1 demonstra que esse modelo animal apresenta-se como boa opção para o desenvolvimento de trabalhos de avaliação da resposta imune humoral frente aos antígenos do BHV-1. A disponibilidade de uma espécie animal de pequeno porte, passível de criação em biotério, e a facilidade de se obter soro em volume adequado para a realização de provas sorológicas e que apresenta boa resposta a um determinado antígeno, mesmo quando inoculado em solução aquosa e sem adjuvante, é de fundamental importância na condução de testes preliminares para o desenvolvimento de vacinas para a profilaxia de infecções em grande animais. 
Quando utilizados de forma isolada, os adjuvantes $\mathrm{Al}(\mathrm{OH})_{3}$ e $\mathrm{DDA}$ cloreto não demonstraram potencializar a produção de anticorpos neutralizantes contra antígenos de BHV-1. Com relação ao $\mathrm{Al}(\mathrm{OH})_{3}$, esse resultado é justificado uma vez que os compostos de alumínio nem sempre induzem resposta imune humoral melhor, ou de maior título, do que os controles aquosos (Gupta et al., 1995). A habilidade do DDA em potencializar a resposta sorológica varia consideravelmente segundo o antígeno utilizado (Dzata et al., 1991). Em algumas situações pode-se observar apenas moderado aumento do título de anticorpos em relação ao grupo-controle (Hilgers et al., 1998). Em outras ocasiões, o DDA pode atuar como forte indutor de imunidade humoral (Katz et al., 1993; Lillehoj et al., 1993; Lindblad et al., 1997). Neste trabalho, considerando a média dos títulos de anticorpos $\left(\log _{2}\right)$ obtida no grupo $\mathrm{E}$, tanto o $\mathrm{Al}(\mathrm{OH})_{3}$ quanto o DDA cloreto, quando utilizados de forma isolada, não demonstraram efeito potencializador da reposta imune humoral de cobaios frente aos antígenos do BHV-1. Entretanto, mesmo não demonstrando grande efeito potencializador da resposta imune humoral, o teste Duncan revelou que o grupo C apresentou resultado semelhante ao grupo A que foi inoculado com $o$ adjuvante padrão (ACF/AIF) universalmente utilizado em experimentos de avaliação de adjuvantes imunológicos.

A associação $\quad \mathrm{Al}(\mathrm{OH})_{3} / \mathrm{DDA} \quad$ cloreto proporcionou efeito sinérgico tendo sido obtidas nesse grupo de animais as maiores médias de títulos de anticorpos neutralizantes aos 21 e 35 dias. O efeito potencializador da resposta imune da associação do DDA com outros adjuvantes também foi demonstrado frente a diferentes tipos de antígenos como SAB em coelhos, toxóide tetânico em humanos e lipopolissacarídio de Brucella abortus em bovinos (Grubhofer, 1995; Dzata et al., 1991). A maior média de soroconversão de todo o experimento (título:3,25), observada após a primeira dose de antígeno, indica ainda que esta associação de adjuvantes tem a habilidade de ativar precocemente a resposta imune humoral de cobaios frente ao BHV-1.

Com relação à inocuidade, após a primeira inoculação todos os animais do grupo A apresentaram forte reação inflamatória localizada, que se intensificou após a segunda dose do antígeno. Em todos os outros grupos avaliados não foram observadas reações adversas, locais ou sistêmicas, demonstrando que o DDA cloreto é inócuo para cobaios.

Os resultados da avaliação da resposta imune celular tipo DTH, realizada aos 60 dias após a imunização dos animais, são apresentados na Tab. 2. Nos grupos B, E e F não foram observadas diferenças quanto ao aumento de espessura da pele, indicando comportamento semelhante em relação à DTH. O aumento médio de $0,5 \mathrm{~mm}$ observado no grupo controle negativo indica que valores muito próximos a esse devem ser considerados normais, possivelmente devido à reação da própria inoculação ou às proteínas do meio de cultura celular. Com isso ratifica-se que vacinas contendo $\mathrm{Al}(\mathrm{OH})_{3}$ como adjuvante não induzem resposta celular do tipo DTH e que, mediante a necessidade desse tipo de resposta, o $\mathrm{Al}(\mathrm{OH})_{3}$ não deve ser utilizado de forma isolada como adjuvante.

Tabela 2. Avaliação da hipersensibilidade cutânea tardia (DTH), 60 dias após a inoculação de cobaias ( $\mathrm{n}=$ 24) com herpesvírus bovino tipo 1 (título: $10^{6,3} \mathrm{ml}$ ) inativado e em diferentes formulações de vacinas

\begin{tabular}{lccc}
\hline \multirow{2}{*}{ Grupo: vacina } & \multicolumn{3}{c}{ Média da espessura da pele $(\mathrm{mm})$} \\
\cline { 2 - 4 } & A (0 horas $)$ & $\mathrm{B}(72$ horas $)$ & $\mathrm{C}(\mathrm{B}$ menos A) \\
\hline A: ACF/AIF & 2,3 & 4,7 & $2,4 \mathrm{~A}$ \\
$\mathrm{~B}: \mathrm{Al}(\mathrm{OH})_{3}$ & 3,2 & 3,8 & $0,6 \mathrm{~B}, \mathrm{C}$ \\
$\mathrm{C}: \mathrm{DDA}$ & 2,7 & 4,5 & $1,8 \mathrm{~A}$ \\
D: $\mathrm{Al}(\mathrm{OH})_{3} / \mathrm{DDA}$ & 2,3 & 3,4 & $1,1 \mathrm{~B}$ \\
E: BHV-1 em solução aquosa & 2,5 & 2,8 & $0,3 \mathrm{C}$ \\
F: Controle-DMEM & 3,0 & 3,5 & $0,5 \mathrm{~B}^{\prime} \mathrm{C}$ \\
\hline
\end{tabular}

ACF/AIF (adjuvante completo/incompleto de Freund); $\mathrm{Al}(\mathrm{OH})_{3}$ (gel de hidróxido de alumínio);

DDA (cloreto de dimetildioctadecilamônio); $\mathrm{Al}(\mathrm{OH})_{3} / \mathrm{DDA}$ (associação gel de hidróxido de

alumínio e DDA); Controle-DMEM (meio para cultivo celular Dulbecco modificado).

Médias seguidas por letras distintas na coluna diferem entre si pelo teste Duncan $(\mathrm{P}<0,05)$. 
A exemplo do DDA brometo (Katz et al., 1993; Lillehoj et al., 1993), os resultados demonstraram que o DDA cloreto também é um potente indutor da resposta celular do tipo DTH. O DDA cloreto quando utilizado como único adjuvante proporcionou aumento de 4,5 vezes à média obtida nos grupos $\mathrm{E}$ e $\mathrm{F}$, e foi o único adjuvante que apresentou resultado semelhante ao do grupo A, considerado modelo padrão para a avaliação da DTH. A associação $\mathrm{Al}(\mathrm{OH})_{3} / \mathrm{DDA}$ cloreto também determinou aumento de resposta celular do tipo DTH, 2,75 vezes superior à média dos grupos $\mathrm{E}$ e $\mathrm{F}$. Embora esse valor possa caracterizar potencialização de resposta celular, ele foi inferior ao alcançado quando o adjuvante DDA cloreto foi utilizado de forma isolada.

Se se considerar o modelo animal e o antígeno utilizado, os resultados descritos neste estudo demonstram que o DDA cloreto, quando utilizado em associação com $\quad \mathrm{o} \quad \mathrm{Al}(\mathrm{OH})_{3}$, apresenta potencial adjuvante das respostas imunológicas humoral e celular em cobaios inoculados com o BHV-1 inativado. Estes resultados, aliados ao baixo custo tanto do DDA cloreto quanto do $\mathrm{Al}(\mathrm{OH})_{3}$, aumentam ainda a perspectiva de avaliação dessa associação de adjuvantes em vacinas, contendo o BHV-1 inativado, para uso em bovinos.

\section{REFERÊNCIAS BIBLIOGRÁFICAS}

ACKERMANN, M.; BELAK, S.; BRITSCH, V. et al. Round table on infectious bovine rhinotracheitis / infectious pustular vulvovaginites virus infection diagnosis and control. Vet. Microbiol., v.23, p.361-363, 1990.

BAHNEMANN, H.G. Bynary ethylenimine as an inactivant for foot-and-mouth disease vírus and its application for vaccine production. Arch. Virol., v.47, p.47-56, 1975.

BRITSCH, V. The modification of the infectious bovine rhinotracheitis virus serum neutralization test. Acta Vet. Scand., v.19, p.497-505, 1978.

CODE of Federal Regulations: Animal and animals products. Washington: United States Agricultural Department, 1999. Title 9, v.1, Parts 1 to 199 .
CORTEZ, A.; HEINEMANN, M.B.; ALFIERI, A.A. et al. Comparação das técnicas de ELISA indireto e de soroneutralização na detecção de anticorpos contra o BHV-1 em amostras de soro de bubalino (bubalus bubalis). Braz. J. Vet. Res. Anim. Sci., v.38, p.146-148, 2001.

DZATA G.K.; WYCKOFF, J.H.; CONFER, A.W. Immunopotentiation of cattle vaccinated with a soluble Brucella abortus antigen with low LPS content: an analysis of cellular and humoral immune responses. Vet. Microbiol., v.29, p.2748, 1991.

GRUBHOFER, N. An adjuvant formulation based on $N$-acetylglucosamyl- $N$-acetylmuramylL-alanyl-D-isoglutamine with dimethyldioctadecylammonium chloride and zinc-L-proline complex as synergists. Immunol. Lett., v.44, p.19-24, 1995.

GUPTA, R.K.; GRIFFIN, J. P. The role of adjuvants and delivery systems in modulation of immune response to vaccines. $A d v$. Exp. Med. Biol., v.397, p.105-113, 1996.

GUPTA, R.K.; ROST, B.E.; RELYVELD, E. et al. Adjuvant properties of aluminum and calcium compounds. Pharm. Biotechnol., v.6, p.229-248, 1995.

GUPTA, R.K.; SIBER, G.R. Adjuvants for human vaccines: Current status, problems and future prospects. Vaccine, v.13, p.1263-1276, 1995.

HANLY, W. C. UIC guidelines for the use of adjuvants in animals. BRL Bull., v.10, p.1-4, 1995.

HILGERS, L.A.T.; NICOLAS, I.; LEJEUNE, G. et al. Effect of various adjuvants on secundary immune response in chickens. Vet. Immunol. Immunopathol., v.66, p.159-171, 1998.

HILGERS, L.A.T.; SNIPPE. H. DDA as an immunological adjuvant. Res. Immunol., v.143, p.494-503, 1992.

JENNINGS, V.M. Review of selected adjuvants used in antibody production. ILAR J., v.37, p.119-125, 1995.

KATZ, D.; INBAR, I.; SAMINA, I. et al. Comparison of dimethyl dioctadecyl ammonium bromide, Freund's complete adjuvant and mineral oil induction of humoral antibodies, cellular immunity and resistance to Newcastle 
disease virus in chickens. FEMS Immunol. Med. Microbiol., v.7, p.303-313, 1993.

LILLEHOJ, H.S.; LINDBLAD, E.B.; NICHOLS, M. Adjuvanticity of dimethil dioctadecyl ammonium bromide, complete Freund's adjuvant and Corynebacterium parvum with respect to host immune response to coccidial antigens. Avian Dis., v.37, p.731-740, 1993.

LINDBLAD, E.B.; ELHAY, M.J.; SILVA, R. et al. Adjuvant modulation of immune responses to tuberculosis subunit vaccines. Infect. Immun., v.65, p.623-629, 1997.

MÉDICI, K.C.; ALFIERI, A.A.; ALFIERI, A.F. Prevalência de anticorpos neutralizantes contra o herpesvírus bovino tipo 1 , decorrente de infecção natural, em rebanhos com distúrbios reprodutivos. Ciên. Rural, v.30, p.347-350, 2000.

MONCADA, C.; TORRES, V.; ISRAEL, Y. Simple method for the preparation of antigen emulsions for immunization. J. Immunol. Methods, v.162, p.133-140, 1993.

RICHTZENHAIN, L.J.; ALFIERI, A.A.; LEITE, R.C. et al. Pesquisa de anticorpos séricos contra o herpesvírus bovino tipo 1 em fêmeas bovinas de propriedades com histórico de problemas reprodutivos, localizadas em 21 estados brasileiros. Arq. Inst. Biol., v.66 (supl.), p.127, 1999.

SILVA, L.C.; TAKIUCHI, E.; ALFIERI, A.F. et al. Efeito adjuvante do cloreto de dimetildioctadecilamônio em preparações de toxóide tetânico. Arch. Vet. Sci., v.8, p.21-29, 2003.
SILVA, R.A.; PAIS, T.F.; APPELBERG, R. Evaluation of IL-12 in immunotherapy and vaccine design in experimental Mycobacterium avium infections. J. Immunol., v.161, p.5578$5585,1998$.

SPIRE, M.F.; EDWARDS, J.F.; LEIPOLD, H.W. et al. Absence of ovarian lesions in IBR seropositive heifers subsequently vaccinated with a modified live IBR virus vaccine. Agri-Pract. Med., v.16, p.33-38, 1995.

STRAUB, O.C. Infectious bovine rhinotracheitis virus. In: DINTER, Z.; MORUN, B. Virus infections of ruminants. Amsterdam: Elsevier Science, 1990. p.71-99.

STRUBE, W.; AUER S.; BLOCK, W. et al. A $\mathrm{gE}$ deleted infectious bovine rhinotracheitis marker vaccine for use in improved bovine herpesvirus 1 control programs. Vet. Microbiol., v.53, p.181-189, 1996.

TAKIUCHI, E.; ALFIERI, A.F.; ALFIERI, A.A. Herpesvírus bovino tipo 1: tópicos sobre a infecção e métodos de diagnóstico. Semina, v.22, p.203-209, 2001.

USER'S guide: statistical analysis system. Release 6.11. Cary, NC: SAS Institute, 1996.

WERGIFOSSE, B.; LEMAIRE, M.; PASTORET, P.P. et al. Establissement d'un plan volontaire de contrôle de la rhinotrachéite infectieuse bovine en Région Wallonne de Belgique. Ann. Méd. Vét., v.141, p.185-186, 1997. 